\title{
Paraplegia
}

\section{Urological Outcome in Female Patients with Spinal Cord Injury: The Effectiveness of Intermittent Catheterisation}

\author{
A. G. Timoney, FRCSI, FRCSEd, P. J. R. Shaw FRCS, \\ Institute of Urology, 172 Shaftesbury Avenue, London, and Spinal Injuries Unit, \\ Royal National Orthopaedic Hospital, Stanmore, Middlesex, UK.
}

\section{Summary}

A review of 52 female patients with spinal cord injury is presented. Twenty five of 38 patients seen within 3 months of their injury were discharged on a clean intermittent catheterisation regime. Of the 14 patients seen at an interval of 3 months or greater after the injury, only 3 practised clean intermittent catheterisation but 8 had a long term indwelling urethral catheter as the method of management.

At 49 months median follow-up, only 14 (50\%) continue on the programme of intermittent catheterisation and $9(32 \%)$ are dry. This lack of success was due to incontinence, despite drug therapy in 17 patients. Recurrent symptomatic urinary tract infection occurred in 10 (36\%). Thirteen of the 14 patients (92\%) on long term indwelling urethral catheter developed complications. Five patients voided normally. Automatic bladder emptying was employed in only 2 patients but was associated with the development of a non-functioning kidney in 1 and severe incontinence in another. Upper tract changes occurred in 7 patients (13\%) including 3 on indwelling catheter drainage and 2 on intermittent catheterisation.

Four patients have had implantation of the Brindley intradural sacral anterior root stimulator because of recurrent symptomatic urinary tract infections and incontinence in all 4. Post-operatively the incidence of infection has been reduced. Improvement in the degree of incontinence is related to the completion of posterior root section. Those patients who have no alternative to long term catheter drainage are managed by the suprapubic route to avoid urethral incompetence. This is combined with catheter clamping for 2 hours daily to maintain bladder capacity and anti-cholinergic therapy to reduce detrusor contractility.

Early referral to a unit with urological support and long term urological follow-up in patients is recommended.

Key words: Spinal cord injury; Clean intermittent catheterisation; Incontinence; Urinary tract infections. 
Female patients, with abnormalities of bladder function following spinal injury, were often treated by indwelling catheter drainage because no effective alternative was available. Clean intermittent catheterisation (CIC) is believed to have a lower morbidity and high patient acceptance with up to $80 \%$ of patients continuing to use it at 5-year follow-up (Maynard and Glass, 1987). Females constitute less than 16\% of the spinally injured population (Guttmann and Frankel, 1966; Thomas and Clarke, 1979; Webb et al., 1984). A study by Pearman (1976) found that females carrying out CIC urinated frequently between catheterisations and had to wear diapers or incontinent pads. Joiner and Lindan (1982) found that the addition of anticholinergic therapy abolished detrusor activity entirely in all patients and enabled 17 of 24 female patients to achieve continence and continue with the CIC programme.

The aim of this review was to establish the urological outcome of female patients with spinal cord injury and whether a policy of clean intermittent catheterisations in female patients continues to be effective after discharge.

\section{Patients and methods}

After admission to the spinal injuries unit all patients have an indwelling urethral catheter for 1 to 2 days. As soon as the patient's condition is stable oral fluid intake is commenced, restricted to $2000 \mathrm{mls}$ per day, and sterile intermittent catheterisation 5 to 6 times per day is started. After full discussion and with the agreement of the patient, our policy in spinal cord injured patients, who do not regain normal micturition, is to carry out long term CIC enabling them to be continent and catheter free. The patients are encouraged to carry out CIC 4 to 5 times per day to achieve a maximum bladder volume of $400 \mathrm{mls}$ or less. Those patients with inadequate hand function to self-catheterise depend on family members or care attendants to carry out the technique.

Whilst in the unit daily urine culture is carried out. Positive urine cultures are not treated unless the patient becomes symptomatic. After discharge antibiotic or antiseptic prophylaxis is not recommended. Patients use 5 catheters per week, immersing them overnight in $1 \% \mathrm{~W} / \mathrm{V}$ solution of sodium hypochloride. Videourodynamic assessment, available since 1983, is carried out within 3 months of admission. Outpatient urological review consists of videourodynamic assessment at 6-monthly intervals for 1 year and 6-monthly ultrasonic scan of kidneys and bladder for the first 2 years; if no abnormality is detected then annual ultrasound scanning is carried out.

Whenever the patient develops hyperreflexia, seen during videocystometry or clinically indicated by episodes of voiding between catheterisations and confirmed by videocystometry, suppression of detrusor activity with anti-cholinergic drugs is begun. During the period under review agents used to suppress detrusor hyperreflexia have included: terodiline, oxybutinin, probantheline and imipramine. The drug dosage is titrated upwards until clinically effective or until side effects intervene. Dry mouth is tolerated but not blurring of vision.

\section{Results}

From October 1981 to January 198952 female patients have been admitted to the 
spinal injuries unit. Their mean age was 35 years (range 14-74) and median followup time from time of injury to was 49 months (range 15 months -33 years). The injury was due to a road traffic accident in 23 , a fall in 11 , suicide or parasuicide attempt in 9, transverse myelitis in 3 and miscellaneous causes in 6 . Twenty nine patients had complete lesions and 23 incomplete. Fourteen patients were tetraplegic with lesions at or above C6. Of the remaining patients, 20 had a lesion at T12 or below (Table I).

Of the 38 patients seen within 3 months of their injury 25 were discharged on CIC, 6 patients were on long term indwelling urethral catheter drainage, 5 voided normally, one tapped and one carried out abdominal straining to achieve bladder emptying. Table II relates the method of management to the level of injury. Fourteen patients were referred to rehabilitation 3 months or more after their injury. At the time of their referral permanent indwelling catheter drainage was the method of management in 8 , intermittent catheterisation in 3 , abdominal straining in 1 , tapping in 1 and 1 patient had an ileal loop diversion.

\section{Clean intermittent catheterisation}

Altogether 28 patients, 25 seen within 3 months of injury and 3 first seen 3 months or more after injury, were initially managed by CIC. Only $14(50 \%)$ remain on the programme (Table III). Five are incontinent to a significant degree, despite anticholinergic therapy and the remaining 9 are socially dry although, of these, 4 are occasionally wet. At the time they ceased to catheterise, 12 suffered repeated episodes of incontinence and this was the reason for dissatisfaction with the method in 10, 1 patient also developed a vesical calculus and 1 a urodynamically proven decrease in bladder compliance. Of the remaining 2 patients, 1 developed bilateral reflux and 1 now voids normally. Incontinence was due to hyperreflexic activity in

Table I Level and extent of injury

\begin{tabular}{lcccc}
\hline & $\mathrm{C} 1-\mathrm{C} 6$ & $\mathrm{C} 7-\mathrm{T} 11$ & $\mathrm{~T} 12$ & and below \\
\cline { 3 - 5 } Complete & 6 & 13 & & 10 \\
Incomplete & 8 & 5 & 20 \\
Total & 14 & 18 & 10 \\
\hline
\end{tabular}

Table II Bladder management in 38 patients at time of discharge

\begin{tabular}{lccc}
\hline & $\mathrm{C} 1-\mathrm{C} 6$ & $\mathrm{C} 7-\mathrm{T} 11$ & $\mathrm{~T} 12$ and below \\
$\begin{array}{c}\text { Intermittent } \\
\text { catheter }\end{array}$ & 5 & 12 & 8 \\
$\begin{array}{c}\text { Indwelling } \\
\text { catheter }\end{array}$ & 1 & 1 & 4 \\
$\begin{array}{c}\text { Normal } \\
\text { voiding }\end{array}$ & 2 & 0 & 3 \\
$\begin{array}{c}\text { Automatic } \\
\text { voiding }\end{array}$ & 0 & 1 & 0 \\
$\begin{array}{c}\text { Abdominal } \\
\text { straining }\end{array}$ & 0 & 0 & 1 \\
\hline
\end{tabular}


Table III Long term outcome of 28 females discharged on CIC programme

\begin{tabular}{|c|c|c|}
\hline & (Median follow-u & p 49 months \\
\hline $\begin{array}{r}\text { Continue } \\
(n=14)\end{array}$ & $\begin{array}{c}\text { Dry } \\
9\end{array}$ & $\begin{array}{c}\text { Wet } \\
5\end{array}$ \\
\hline $\begin{array}{l}\text { Change of } \\
\quad(n=14)\end{array}$ & 2 & 12 \\
\hline
\end{tabular}

Table IV Management change in 14 patients established on CIC at time of discharge

\begin{tabular}{lllc}
\hline & C1-C6 & C7-T11 & T12 and below \\
\cline { 1 - 2 } \cline { 1 - 1 } & 2 & 4 & 0 \\
Sacral stimulator & 0 & 3 & 0 \\
Suprapubic catheter & 1 & 1 & 1 \\
Loop diversion & 0 & 1 & 0 \\
Normal voiding & 0 & 0 & 1 \\
Total & $3(5)$ & $9(14)$ & $2(9)$ \\
\hline
\end{tabular}

$(\quad)=$ Numbers on discharge

Table V Management change in 7 patients on long term indwelling urethral catheter

\begin{tabular}{lllll}
\hline & $\mathrm{C} 1-\mathrm{C} 6$ & $\mathrm{C} 7-\mathrm{T} 11$ & $\mathrm{~T} 12$ and below \\
${$\cline { 1 - 2 }$} }$ & 0 & 0 & -2 \\
Sacral stimulator & 1 & & 0 & 0 \\
Suprapubic catheter & 1 & 0 & 2 \\
Loop diversion & 1 & 0 & 0 \\
Total & $3(5)$ & $0(4)$ & $4(5)$ \\
\hline
\end{tabular}

$(\quad)=$ Numbers on discharge

15, urethral incompetence in 1 and poor patient compliance in 1. Table IV summarises the change in urinary management at follow-up.

\section{Urinary infections}

Ten patients (36\%) on CIC developed symptomatic injury tract infection after discharge on at least 3 occasions in a 12-month period. A clinical urinary tract infection is defined as a systemic febrile illness associated with a positive urine culture; other signs of abdominal or pelvic irritation such as lower abdominal pain, reflex sweating, increased spasticity or hyperreflexia which responds to treatment of the urosepsis. There were no other lower tract complications.

\section{Upper tract change}

Two patients developed upper tract changes while on CIC. At 24 months, mild unilateral dilatation was seen on ultrasound in one, videocystometry revealed a 


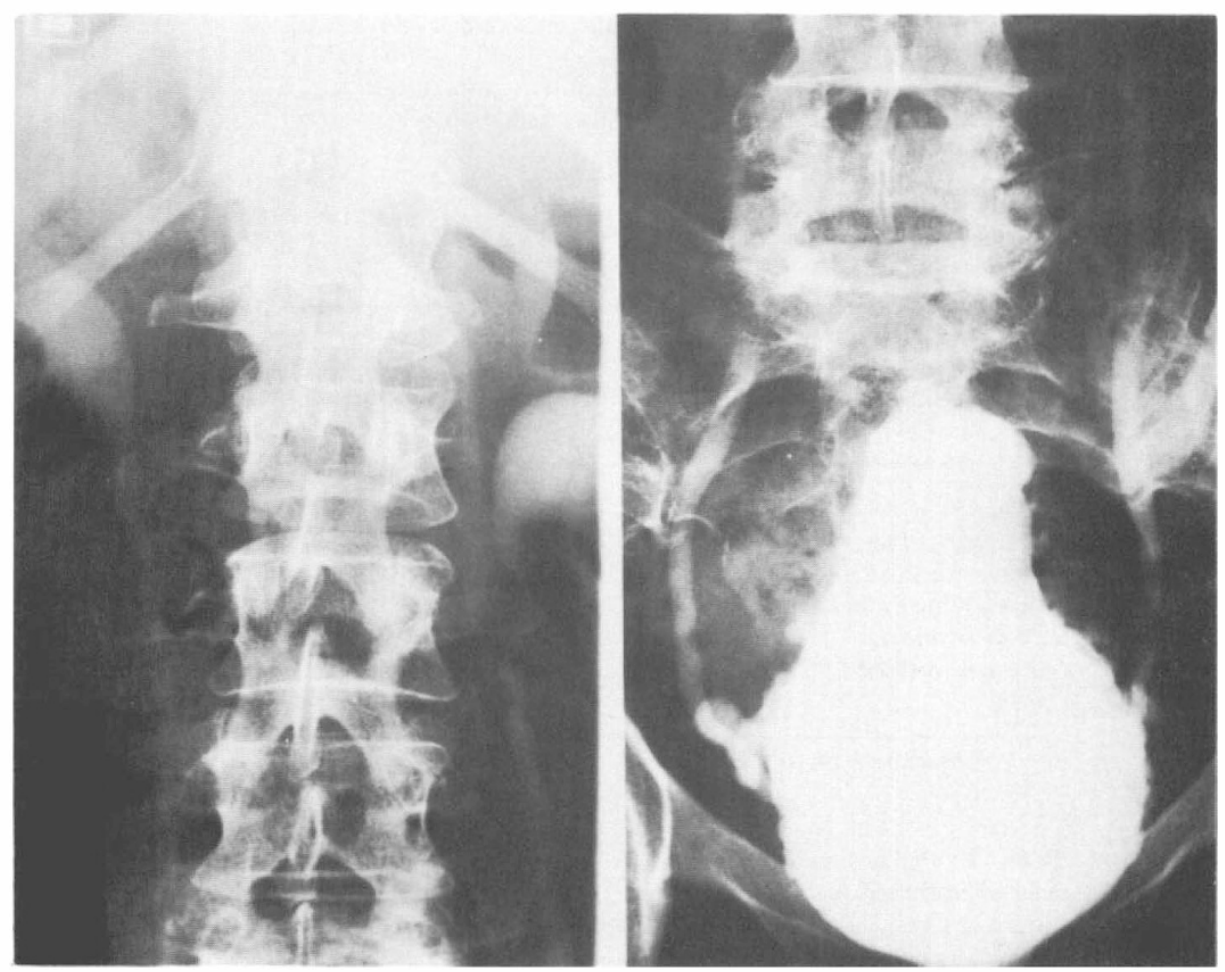

Figure A 54-year-old female with a complete C6 lesion, 4 months post-injury, managed by clean intermittent catheterisation, developed bilateral reflux associated with detrusor hyperreflexia and detrusor sphincter dyssynergia.

hyperreflexic bladder with diminished compliance, reflux was not demonstrated, and was treated conservatively. At 4 months another patient, while on anticholinergic therapy, developed bilateral reflux, seen during videocystometry, associated with high pressure hyperreflexia and detrusor neck dyssynergia (Fig. 1). Repeated videocystometry indicated progressive deterioration in bladder compliance. The management has been changed to long term indwelling catheter drainage and anticholinergic suppression.

\section{Permanent indwelling catheter drainage}

Fourteen patients were managed by long term indwelling urethral catheter drainage. Sixteen complications developed in 13 patients (92\%). Leakage occurred in 5 due to the development of a patulous or incompetent urethra in 4 and bypassing in 1. Recurrent symptomatic urinary tract infections were a probelm in 5 patients associated with a vesical calculus in 2 . Autonomic dysreflexia due to recurrent catheter blockage developed in 1 , and 3 patients developed changes in the upper tract, bilateral reflux in 2 and dilatation in 1. During the period under review the method of management has been changed in 7 patients (Table V).

Of the remaining 10 patients, 2 carried out abdominal straining to help voiding. 
Three years after her injury 1 patient was referred because of incontinence, changed to clean intermittent catheterisation and is dry. Seventeen years postinjury a 57-year-old patient developed prolapsing haemorrhoids but declined intermittent catheterisation. Two patients were managed by automatic voiding. One patient, with a T9 lesion, 4 years post-injury, was found to have a non-functioning kidney due to high pressure hyperreflexia and associated reflux. A nephrectomy and clam cystoplasty were carried out. She now carries out intermittent catheterisation, is dry and has stable renal function. A 23-year-old patient, with an incomplete C6 lesion 5 years post-injury complained of severe incontinence, videourodynamics revealed a small capacity bladder with high pressure hyperreflexia. A Brindley intradural sacral anterior root stimulator was implanted, with division of the S2-3 posterior roots and crushing S4-5 bilaterally. One year post-operatively she is dry, has a bladder capacity of $540 \mathrm{ml}$ and empties to completion on stimulation. The 1 patient with an ileal loop diversion was admitted 15 years post-injury. Mild bilateral dilatation was seen on upper tract ultrasound 13 years post-operatively.

\section{Discussion}

Intermittent catheterisation, clean or aseptic, is now the most common method of bladder management on discharge after rehabilitation following SCI (Stover, 1985). In this study 28 female SCI patients were managed on a CIC regime. At median follow-up, 49 months after injury, only 14 patients $(50 \%)$ were continuing with this method. This contrasts with continued use rates of $82 \%$ to $86 \%$ reported in studies of mixed populations (Maynard and Diokno, 1982; Maynard and Glass, 1987). Continuing unacceptable incontinence was the principal reason for changing the bladder management plan in 10 of the 14 patients. As over one-third of those patients persisting with $\mathrm{CIC}$ continue to leak urine to a significant degree we expect that with a longer period of follow-up the number carrying out CIC will decline. Unlike others, (Hill and Davies, 1988), we do not believe that this failure is due to a lack of patient discipline. In the female population anti-cholinergic therapy is not adequate to reduce detrusor contractility sufficiently to achieve continence. Interruption of the sacral reflex arc, with or without sacral root stimulator implantation, or augmentation cystoplasty is necessary to sufficiently control high pressure detrusor contractility to achieve this aim (McGuire and Savastano, 1983).

Urological complications occurring in these 28 patients included recurrent symptomatic urinary tract infections in $10(36 \%)$. We agree with Stickler and Chawla, 1988, that limiting the use of antibiotics to prevent the emergence of multi-drug resistance is necessary. We avoid prophylaxis in CIC patients and only treat symptomatic urinary tract infection. The incidence, however, of symptomatic urinary tract infection in this series, as others, of female patients carrying out CIC is high (McGuire and Savastano, 1986). This contrasts with a much lower incidence of febrile urinary tract infection in a population of males and females carrying out CIC where asymptomatic bacteriuria was routinely treated with antimicrobial agents (McGuire and Savastano, 1983). Prompt treatment of asymptomatic bacteriuria, however, has failed to significantly reduce the incidence of symptomatic episodes (Maynard and Diokno, 1984). This suggests that bacteriuria in females is more likely to result in symptomatic infection than in males. A practical technique of microwave sterilisation of catheters at home has recently been 
described and might be of benefit in reducing the incidence of this complication (Silbar et al., 1989).

In this group of 28 patients, a vesical calculus developed in only 1 , who did not comply with the CIC programme. There were no other lower tract complications on CIC, which agrees with the findings of others (McGuire and Savastano, 1986). In contrast, upper tract changes developed in 2. One patient developed bilateral vesicoureteric reflux and 1 dilatation while on CIC. Both had hyperreflexic detrusor activity on cystometry and both were noted to have diminished bladder compliance. We continue to observe the patient with dilatation as reflux and dilatation have previously been reported in 1 patient on CIC and resolved spontaneously (Joiner and Lindan, 1982). The patient with bilateral reflux, developed deteriorating bladder compliance on successive videocystometrograms and was treated with an indwelling catheter and anti-cholinergic suppression.

We believe that suppression of high pressure detrusor activity may reduce the high incidence of upper tract change reported after the use of a long term indwelling catheter (Hackler, 1982). This incidence of upper tract change in patients on CIC, due to detrusor sphincter dyssynergia, indicates the need for long term observation even in female patients where, is has been suggested, a lower urethral outflow resistance, resulting in incontinence, might be considered to preclude the development of upper tract deterioration (Maynard and Glass, 1987). Of the 5 patients with a lesion above $\mathrm{C} 7$, discharged on CIC, 4 were persistently wet, resulting in 3 changing to another management regime. This high failure rate in tetraplegic patients with limited hand function is similar to others (Lindan et al., 1987; Hill and Davies, 1988). Our results indicate that there appears to be little alternative to indwelling catheters for these patients. We are now inserting them suprapubically to avoid the lower tract complications that ensue after long term urethral catheterisation (McGuire and Savastano, 1986). This is combined with catheter clamping for up to 2 hours daily to maintain bladder capacity and anticholinergic therapy to reduce detrusor contractility. One patient, with complete lesion at C6 level, and little ability to transfer independently is awaiting a sacral root stimulator (Brindley et al., 1982). This device, however, only offers escape from an indwelling catheter in those quadriplegics who can transfer independently or have full-time care attendants. Four patients, 1 with incomplete cervical lesions and 3 with complete thoracic lesions have had sacral anterior root stimulator implantation for recurrent urinary tract infection and incontinence. Post-operative urinary tract infection has not occurred in 2 patients and has been less frequent in 2. The improvement in continence is related to the extent of posterior root section. Patients with bilateral destruction of the posterior sacral roots 2 to 5 , obtained by section of roots S2 and S3 and crushing root S4 and 5, are dry whereas patients with incomplete section of the roots have occasional episodes of reflex incontinence.

In conclusion, 25 of 38 patients referred within 3 months of injury were discharged on CIC. Continued use rates of CIC in the female spinal cord injured population is lower than in men, the difference in this series is due to persistence incontinence, refractory to anticholinergic suppression. CIC is associated with few complications apart from urinary tract infection. In spite of the low incidence of upper tract change it is recommended that these patients remain under lifelong supervision. 


\section{References}

BRINDley GS, Polkey CE, Rushton DN 1982 Sacral anterior root stimulators for bladder control in paraplegia. Paraplegia 20:365-381.

GutTman L, Frankel H 1966 The Value of intermittent catheterisation in the early management of traumatic paraplegia and tetraplegia. Paraplegia 4:63-82.

HACKLER RH 1982 Long term suprapubic cystostomy drainage in spinal cord injury patients. British Fournal of Urology 54:120-121.

Hill VB, DAvies WE 1988 A swing to intermittent clean self catheterisation of the neuropathic bladder for the dextrous spinal cord patient. Paraplegia 26:405-412.

JOINER E, LINDAN R 1982 Experience with self intermittent catheterisation for women with neurological dysfunctions of the bladder Paraplegia 20:147-153.

LINDAN R, LEFFLER EJ, BODNER D 1987 Urological problems in the mangement of quadriplegic women. Paraplegia 25:381-385.

MAYNARD FM, DIOKNO AC 1982 Clean intermittent catheterisation for spinal cord injured patients. Fournal of L'rology 128:477-480.

MAYNARD FM, DIOKNO AC 1984 Urinary infection and complications during clean intermittent catheterisation following spinal cord injury. Fournal of Urology 132:943-946.

MAYNARD FM, GLASS J 1987 Management of neuropathic bladder by clean intermittent catheterisation: 5 year outcomes. Paraplegia 25:106-110.

MCGuIRE EJ, JoAN SAVASTANO 1983 Long-term follow-up of spinal cord injury patients by intermittent catheterisation. Fournal of Urology 129:775-776.

MCGUIRE EJ, JOAN SAVASTANO 1986 Comparative urological outcome in women with spinal cord injury. Fournal of Urology 135:730-731.

Pearman, JW 1976 Urological follow-up of 99 spinal cord injured patients initially managed by intermittent catheterisation. British fournal of Urology 48:297-310.

Silbar EC, Cicamec JF, Burke Barbara M, BraCKen RB 1989 Microwave sterilization: a method for home sterilization of urinary catheters. Fournal of Urology 142:88-90.

Stover SL et al. 1985 3rd Annual Report National Spinal Cord Injury Statistical Centre, University of Alabama, Birmingham, AL.

STICKLER DJ, CHAWLA JC 1988 An appraisal of antibiotic policies for urinary tract infections in patients with spinal cord injuries undergoing long-term catheterisation. Paraplegia 26:215-225.

ThOMAS DG, CLARKE SJ 1979 The urological status of 86 females following spinal cord injury. British Fournal of Urology 51:515-517.

WEBB DR, FITZPATRICK JM, O'FLYNN JD 1984 A 15-year follow-up of 406 consecutive spinal cord injuries. British Fournal of Urology 56:614-617. 